\title{
The burden of clinically significant symptoms of common and severe mental disorders among adults in Vietnam: a population-based cross-sectional survey
}

Trang Nguyen ${ }^{1,2^{*}}$, Tuan $\operatorname{Tran}^{2}$, Ha $\operatorname{Tran}^{2}$, Thach $\operatorname{Tran}^{1,2}$ and Jane Fisher ${ }^{1}$

\begin{abstract}
Background: Vietnam has limited evidence about the burden of common and severe mental disorders among adults to inform policy. The aim of this paper was to estimate the prevalence of common and severe mental disorders among adults and factors associated with them in Vietnam.

Methods: We conducted a cross-sectional household survey among people aged at least 16 years in Thanh Hoa and Ben Tre provinces which are nationally representative of the North and the South of Vietnam. The World Health Organization Self-Reporting Questionnaire 24 was used to screen for clinically significant symptoms of common and severe mental disorders at the individual level. Household characteristics were obtained in faceto-face interviews with the household heads. A multilevel mixed-effects logistic regression model was used to identify associated factors of the common and severe mental disorders.

Results: Among 611 households which included 1528 adults, the point prevalence of clinically significant symptoms was $14.4 \%$ for common mental disorders and $8.2 \%$ for severe mental disorders after weighting by age groups. Common mental disorders were associated with social factors including lived in a Northern rather than a Southern province, disadvantaged household economic status, in which a family member(s) misused alcohol, the family lacking links to social organisations able to provide instrumental support, and the individual not having completed primary school. Severe mental disorders had fewer associations with social factors compared to common mental disorders, but were associated with living in the Northern province, disadvantaged household economic status, family violence and being older than 50 years.

Conclusions: The prevalence of clinically significant symptoms of common and severe mental disorders among adults in Vietnam was higher than in high income countries and had a strong association with household characteristics. The result indicates that a community-based approach to reduce household risk factors and to provide instrumental support might be an effective strategy to alleviate the burden of mental health problems in Vietnam.
\end{abstract}

Keywords: Common and severe mental disorders, Risk factors, Vietnam, Adults

\footnotetext{
* Correspondence: trang.t.nguyen@monash.edu

${ }^{1}$ School of Public Health and Preventive Medicine, Monash University, 553 St Kilda Road, Melbourne, Victoria 3004, Australia

${ }^{2}$ Research and Training Centre for Community Development (RTCCD), No 39, lane 255, Vong street, Hanoi, Vietnam
}

C The Author(s). 2019 Open Access This article is distributed under the terms of the Creative Commons Attribution 4.0 International License (http://creativecommons.org/licenses/by/4.0/), which permits unrestricted use, distribution, and reproduction in any medium, provided you give appropriate credit to the original author(s) and the source, provide a link to the Creative Commons license, and indicate if changes were made. The Creative Commons Public Domain Dedication waiver (http://creativecommons.org/publicdomain/zero/1.0/) applies to the data made available in this article, unless otherwise stated. 


\section{Background}

Mental disorders in low and middle-income countries (LMICs) are becoming more widely recognized due to its burdens and associating factors [1]. Mental disorders contributed to more than $40 \%$ of years lived with disability (YLDs) [2, 3] and nearly 15\% of disability-adjusted life years (DALYs) globally [4]. The term common mental disorders (CMDs) is the widely-accepted descriptor for non-psychotic anxiety, depressive, adjustment and somatic disorders which are potentially detectable in primary care [5]. Severe mental disorders (SMDs) include disorders characterised by psychotic symptoms such as schizophrenia and bipolar affective disorder [6]. The World Health Organization (WHO) classifies psychotic symptoms as abnormalities in thinking or disorganized behaviour: delusions, hallucinations, neglect of self-care, inability to complete usual responsibilities and either lack of volition or the excessive drive revealed in manic states [7].

Depressive disorders was the third leading cause of disability in 2017 [3]. It is estimated that $80 \%$ of the people experiencing both these conditions live in LMICs [8]. Steel et al's (2014) recent systematic review of 174 population-based studies from 63 countries, reported a pooled 12-month period prevalence of anxiety and depression of $20 \%$. The review concluded that the prevalence was similar in LAMICs and high-income countries (HICs), and that approximately one in three people experience a CMD at some point during their lifetime. Lifetime prevalence in LMICs was estimated to be lower than that in HICs [9]. However, there are some influential limitations in this review that warrant consideration in interpreting these conclusions. First, there was no critical engagement with whether the data collection tools (including diagnostic interviews) had been appropriately culturally verified or formally validated for the cultural contexts in which they were administered [10]. Second, there was also no consideration of cultural differences in emotional literacy or the impact on disclosure of severe stigma against people with mental disorders. It was not clear whether strategies to enable the participation of people with low literacy had been considered in evaluating study methodologies. If questions are not comprehensible people are likely to answer no and this leads to underestimates of prevalence.

Establishment of the prevalence of severe mental disorders in resource-constrained settings has been difficult due to insufficient mental health specialists and lack of research capacity in psychiatric epidemiology. The prevalence has most commonly been established by ascertainment of psychotic symptoms rather than diagnoses of disorders [11, 12]. In 2012 Nuevo et al. analysed data contributed by 256, 445 participants in 52 countries to the World Health Survey to establish the prevalence of psychotic symptoms. The cross-national survey employed the
Composite International Diagnostic Interview (CIDI) administered trained by non-mental health professionals to detect specific psychotic symptoms, but not to form clinical diagnoses. The prevalence of having at least one psychotic symptom varied widely from 0.66 to $45.84 \%$. The authors suggested that the potential reason for this wide range was cultural differences among countries. However, the publication did not mention the procedure of adapting the CIDI for specific countries. In addition to the cultural difference, the lack of formal validation might contribute to the wide variation of the prevalence of psychotic symptoms in the multi-national survey [13].

\section{Burden of mental disorders in Vietnam}

There have been five investigations reported to date of the burden of CMDs and SMDs among adults in the general population in Vietnam in international peer-reviewed journals in English. Among these, one summarised the main findings of a Ministry of Health report, but did not include any information about method, sample and data analysis [14]. Four papers described four original research studies. One survey was conducted in a Southern province (Hau Giang) applying a multistage probabilistic cluster sampling frame with the commune or hamlet as the sampling unit. The investigators conducted interviews with 3039 people who were older than 17 years. Data collectors were mental health physicians, mental health nurses and general staff. The CIDI was culturally adapted in several stages including a comprehensive review of emotional states in Vietnamese ethnographic studies, and psychometric tests with high internal consistency $(r=0.87-0.95)$ and reliability $(r=0.81-0.89)$. The data collection tool consisted of a depression scale (26 items), an anxiety scale (13 items), and a somatisation scale (14 items) to measure the prevalence of depression and anxiety [15]. The household cross-sectional survey in two southern provinces (Da Nang and Khanh Hoa) used a four-stage cluster sampling strategy. The investigators included 4981 adults who were 18 or older. The face-to-face interviews were implemented by trained lay data collectors. The SRQ20 validated in Vietnam with the cut-off of 6/7 was used to screen for CMDs among the study population [16]. Another paper in Vietnam was a pre- and post Xangsane typhoon survey with 797 adults $(18+)$ in Da Nang - a southern province. Data were collected by trained interviewers using validated SRQ20 with cut-off of $7 / 8$ for CMDs [17]. Finally, the WHO survey was conducted in 52 countries including Vietnam. The CIDI was used by trained staff to screen for SMDs among 4174 adults (18+). This data collection tool was translated into Vietnamese using a specified protocol. There was lack of information about which province the study was conducted in [13].

The Ministry of Health reported that the prevalence of depression and anxiety among the population were 2.8 
and $2.6 \%$ respectively [14]. The two peer-review articles revealed a wide variation of depression and anxiety prevalence. A survey among adults in the Southern Hau Giang province found that the prevalence was 1.2\% (Standard Error: 0.7) for depression, 4.0\% (Standard Error: 0.2) for anxiety [15]. The study in Da Nang and Khanh Hoa provinces reported that around $20 \%$ of adults have clinically significant symptoms of CMDs [16]. The prevalence in another study in Da Nang was $20.7 \%$ before the typhoon [17]. These findings suggest that the prevalence of CMDs among adults in Vietnam was estimated by screening instruments to be higher than among those using diagnostic tools.

The Ministry of Health reported the prevalence of schizophrenia to be $0.5 \%$ but means of ascertaining this was not clear [14]. The WHO survey found that the prevalence of having at least one psychotic symptoms in Vietnam was $0.66 \%$ (Standard Error: 0.20 ) at the population after weighted and sex-age standardization [13].

In general, the burden of CMDs and SMDs in Vietnam were estimated from sub-populations such as some provinces in the south of Vietnam, or from women during the perinatal period in the northern rural area. Methodologies used were inconsistent among these studies.

The four original studies in Vietnam reported a limited set of protective and risk factors such as age, gender, marital status, education, occupation [13-16]. In general, especially in rural areas, most families live in multi-generation arrangements where family members are strongly connected, share social capital, economic status, supports from government or resource groups, and co-experience adverse events. In addition, most people with psychotic disorders are cared by their family members. Therefore, mental health problems have to be understood within the family environment.

In order to address the policy need and limitation of the existing evidence in Vietnam, the aim was to estimate the burden of CMDs and SMDs among adults in Vietnam. In particular, this study aimed to (1) estimate the prevalence of clinically significant symptoms of CMDs and SMDs among adults in Vietnam; and (2) identify factors at both individual and family levels associated with CMDs and SMDs among adults in Vietnam.

\section{Methods}

\section{Study design}

The study was a cross-sectional household survey completed in May and June 2013.

\section{Setting}

Vietnam is a World Bank classified lower-middle income country, with a population of more than 90 million people in Southeast Asia [18]. The North and the South of Vietnam have different socio-political characteristics.
Historically, the two areas were ruled by different Kings with different cultures. More recently, the South area was influenced first by French colonisers and then the United States, whereas the North of Vietnam was influenced more by the Soviet Union and China. There remain significant differences between the two areas in terms of culture, idiomatic language, pronunciation, living standards, and social behaviours. The survey was conducted in two provinces which represent the north and the south of Vietnam. Thanh Hoa is the Northern province with the third highest population in Vietnam with 3.496 .600 people living in 27 districts. The province has 6 coastal, 11 mountainous and 10 plain land districts and a capital city. At the time of the survey the average income per capita per month was approximately 1.6 million Vietnam dong (approximately USD 82) [19]. Ben Tre - a southern province has a population of approximately 1.26 million people living in one city and eight districts. All city and districts are in the plain land. The average income per capita per month was nearly 2.2 million Vietnam dong (more than USD 100) [20].

\section{Random selection of households and sample size}

A cluster sampling method was used. At the provincial level, 30 communes were randomly selected from the list of communes provided by the provincial level Departments of Health and Labour, Invalids and Social Affairs. In each selected commune, a list of households was made by the commune administrators and 15 households were selected randomly from it. Ten households were visited and, if no-one was at home, a household was selected from the replacement list. All adults who were older than 16 years in the households were invited to participate in the survey. Household members were defined as members who have had meals together for at least 6 months. The household head was defined by the local authority. Commonly the household head is the most powerful decision-maker in the family.

\section{Data collection tools and sources}

The structured interview schedules included standardised instruments and study-specific questions. Two forms of data were collected: (1) Individual-level information was collected by self-reported questionnaires. The questionnaires included the SRQ and other background information such as age, education, and gender; (2) Household socioeconomic characteristics were ascertained by interviewing the head of the household.

Specific tools and information used in this survey were described in Table 1.

\section{Procedure}

Local staff of the provincial level Department of Health and Department of Invalids and Social Affairs were 
Table 1 Tools used for data collection

\begin{tabular}{|c|c|c|}
\hline Variable & Tool & Description \\
\hline \multicolumn{3}{|l|}{ Individual level } \\
\hline $\begin{array}{l}\text { Symptoms of common } \\
\text { and severe mental } \\
\text { disorders }\end{array}$ & WHO Self Reporting Questionnaire (SRQ) & $\begin{array}{l}\text { The screening tool consists of } 20 \text { questions related to common non- } \\
\text { psychotic mental disorders and four questions related to psychotic } \\
\text { symptoms [12]. There are two formal validity studies of SRQ } 20 \text { items in } \\
\text { Vietnam. The first study (2004) was conducted in a Northern province } \\
\text { among } 2000 \text { female caregivers to validate the SRQ20 against the diagnosis } \\
\text { of a professor of paediatric psychiatry. The cut-off point was } 7 / 8 \text { [21]. The } \\
\text { second study in } 2006 \text { included a community sample of } 500 \text { people aged } \\
\text { from } 18 \text { to } 60 \text { in a rural northern province presented an optimal cut-off } \\
\text { point of } 5 / 6 \text {. SRQ } 20 \text { items was validated against psychiatrists [22]. This } \\
\text { study used the cut-off point of } 6 / 7 \text { to calculate the prevalence of clinically } \\
\text { significant symptoms of CMDs among adults in Vietnam due to the } \\
\text { similarity of the study participants. } \\
\text { The SRQ includes } 4 \text { items assessing symptoms of severe mental disorders } \\
\text { including (1) has somebody been trying to harm you in some way, (2) are } \\
\text { you a much more important person than most people think, (3) have you } \\
\text { noticed any interference or anything else unusual with your thinking, (4) } \\
\text { have you ever heard voices without knowing where they come from or } \\
\text { which other people cannot hear [12]. }\end{array}$ \\
\hline
\end{tabular}

Household level

Household economic status

Alcohol abuse

Family violence

Social capital

Specific adverse life event
One question addressing household economic status

One question addressing whether any household member abused alcohol

Short form of domestic violence screening tool (HITS) [24].

Short version of the modified Adapted Social Capital Assessment Tool (SASCAT) [25]

One question assessing experiences of adverse life events
Subjective self-assessment of household heads in terms of their household economic status compared to other neighbours in their commune [23].

The household heads identify whether a household member was abusing alcohol.

The original four-item scale was developed to identify domestic violence in term of Hurts, Insults, Threatens and Screams (HITS) with 5-point frequency format at individual level. The score ranges from 4 (no family violence) to 20 (frequent family violence) [24]. This scale was adapted to screen the family violence by asking whether any household member suffering from such domestic violence.

The SASCAT comprises nine items divided into two subscales: structural and cognitive social capital. The structural social capital reflects the connectedness of the household with the community such as participation in organizations, degree of citizenship (the involvement in voting, campaign activities at commune or provincial levels), specific collective action (together with other neighbour to address a specific problem in the community) and links to groups with resources (such as local government or aid agencies). The cognitive social capital describes the feelings of sense of community such as reciprocity, and sharing. It consists of emotional support, instrumental support (food, money, etc), trust, social harmony (getting along with others in the community), sense of belonging (attachment to the community), and perceived fairness (whether others in the community take advantage of people) [26]. This tool was validated in Vietnam with nearly $80 \%$ of accurate interpretation of all questions among caregivers and data collectors. SASCAT was also reported as a valid tool in terms of psychometric and cognitive validation $[27,28]$.

Have the following events occurred in the previous 3 years: household items stolen/robbed, threatening of losing or lost rights of inheritance, threatening or lost land/property ownership. employed as data collectors due to their familiarity with local accents, customs, and access routes to communes. They were trained for 3 days by the research team from the Research and Training Centre for Community Development (RTCCD) in Hanoi. Only staff who fulfilled all requirements in terms of communication skills and understanding of the questionnaire, protection of confidentiality and ensuring data integrity were employed as data collectors.
All potential participants were informed by local authorities that they were to be invited for interviews. At the day of the interview, village heads guided the data collectors to the selected households. All household members who were adults were given separately an oral or written plain language description of the study and were asked to sign a consent form. Those who could not write provided a thumbprint or verbal consent witnessed by an independent observer. After interviewing the 
household heads to collect household characteristics, all members who were older than 16 years old were assigned into different private rooms to complete the written self- report the SRQ with 20 items for symptoms of CMDs and 4 items for psychotic symptoms. For those who had low literacy, interviews were conducted by the data collectors.

The research team supervised all data collectors and selected randomly $5 \%$ of the completed questionnaires to reinterview participants for quality assurance. In addition, questionnaires were checked by supervisors in the field for missing values and inconsistent responses, to enable data collectors to go back to the household to amend possible errors.

Completed consent forms and paper-based questionnaires gathered by the data collectors were returned to the research team at the end of each working day for secure storage in a locked cabinet at the provincial level Department of Labour, Invalids and Social Affairs office. Then it was transported in a locked bag with the research team for secure storage and data entry at the RTCCD office.

\section{Data management and analysis}

No name was recorded in the questionnaires, only the codes of provinces, communes and households were used for data entry and data analysis. Family members shared the same family code, but different personal codes to allow the researchers to identify data of individual and household levels.

A double data entry method was conducted using the Microsoft Access 2013 (Microsoft Corp, USA). The paper records were stored securely at RTCCD office and only researchers had access to the original data.

Data analyses were completed in two steps using Stata, Version 13.0 (StataCorp LP, College Station, Texas, USA), with statistical significance set at $p$-value less than 0.05 . Step 1 used descriptive analyses to calculate the community prevalence and $95 \%$ confidence intervals. A score of 6 and above on the SRQ20 was used as the indicator of clinically-significant symptoms of CMDs. The cut-off score of $5 / 6$ was reported in the validity study of SRQ-20 with a sensitivity of $85 \%$, and a specificity of $46 \%$ [22]. Participants who reported at least one psychotic symptom were classified as having a clinically significant symptom of an SMD [12]. People who reported both clinically significant symptoms of CMDs and any psychotic symptoms were classified in the SMD group [29]. The prevalence of CMDs and SMDs were weighted using the standard proportion of age and sex groups among the Vietnam population in 2013 [30].

Step 2, univariate analyses were used to compare individual characteristics between groups of people with and without clinically-significant symptoms of CMDs or SMDs. The same method was also employed to identify differences in household characteristics between those with or without member having clinically significant symptoms of CMDs or any symptom of SMDs.

In step 3, the binary outcome (CMDs or SMDs) a value of 0 was given to the category of having no clinically significant symptoms of CMDs or SMDs, and a value of 1 to the category of having clinically significant symptoms. The data of this study had two levels, with individuals nested within households. All people in the same household shared common socio-economic characteristics. Therefore, two-level mixed-effects logistic regressions with random intercepts and fixed coefficients including both household and individual characteristics were used [31].

\section{Results}

In total 643 households were approached, among which 32 households were not included either because the household heads were not at home at the time the study team visited or declined participation. In total, 611 households accepted the invitation to contribute data, giving a recruitment fraction of 95\%. Overall, 1528 individual household members aged more than 16 years contributed data.

\section{Socio-economic characteristics of the study sample}

Most households were of mid-level or disadvantaged economic status $(72.6 \%)$ and had experienced specific adverse events in the previous 3 years. Regarding the cognitive social capital, a majority of households reported experiencing emotional support, trust, social harmony, and sense of belonging. Insignificant numbers reported any experiences of family violence. Among 1528 participants, most were aged over 24 years and less than $10 \%$ had completed tertiary education. More women than men contributed data (see Table 2).

\section{The prevalence of clinically significant symptoms of CMDs and SMDs}

Among the 1528 participants, 251 (16.4\% (95\% Confidence Interval: $14.65-18.37 \%))$ had SRQ20 scores greater than 6/20, and 132 (8.6\% (95\% Confidence Interval: 7.32$10.16 \%)$ ) reported at least one psychotic symptom. After weighting for age and sex, the population point prevalence of CMDs was $14.2 \%$ (95\% Confidence Interval: $14.16 \%$ 14.18), and the population lifetime prevalence of SMDs was $8.1 \%$ (95\% Confidence Interval: 8.12-8.14\%).

\section{Factors associated with CMDs}

In the uncontrolled univariate analyses, individual characteristics including gender, age, and education were significantly associated with CMDs (see Table 3). The household factors which were significantly associated with CMDs were province, residence of urban or rural area, economic status, and some social capital items 
Table 2 Social characteristics of households and individuals in Vietnam which contributed data

\begin{tabular}{|c|c|c|c|}
\hline Variables & $\begin{array}{l}\text { Thanh Hoa } \\
\text { n (\%) }\end{array}$ & $\begin{array}{l}\text { Ben Tre } \\
\mathrm{n}(\%)\end{array}$ & $\begin{array}{l}\text { Total } \\
\text { N (\%) }\end{array}$ \\
\hline \multicolumn{4}{|l|}{ Household level } \\
\hline Number of households & $294(48.1)$ & $317(51.9)$ & $611(100 \%)$ \\
\hline \multicolumn{4}{|l|}{ Economic status } \\
\hline Disadvantaged & $51(17.3)$ & $50(15.8)$ & $101(16.5)$ \\
\hline Mid-level & $181(61.6)$ & $174(54.9)$ & $355(58.1)$ \\
\hline Advantaged & $62(21.1)$ & $93(29.3)$ & $155(25.4)$ \\
\hline \multicolumn{4}{|l|}{ Residence } \\
\hline Urban & $50(17.0)$ & $169(53.3)$ & $219(35.8)$ \\
\hline Rural & $244(83.0)$ & $148(46.7)$ & $392(64.2)$ \\
\hline \multicolumn{4}{|l|}{ Alcohol abuse in the family } \\
\hline Yes & $23(7.8)$ & $52(16.4)$ & $75(12.3)$ \\
\hline No & $271(92.2)$ & $265(83.6)$ & $536(87.7)$ \\
\hline \multicolumn{4}{|l|}{ Family violence } \\
\hline Yes & $9(3.1)$ & $5(1.6)$ & $14(2.3)$ \\
\hline No & $285(96.9)$ & $312(98.4)$ & $597(97.7)$ \\
\hline \multicolumn{4}{|l|}{ Structural social capital } \\
\hline Participation in organizations & $72(24.5)$ & $145(45.7)$ & $217(35.5)$ \\
\hline Degree of citizenship & $204(69.4)$ & $227(71.6)$ & $431(70.5)$ \\
\hline Specific collective actions & $90(30.6)$ & $136(42.9)$ & $226(37.0)$ \\
\hline Links to groups with resources & $92(31.3)$ & $196(61.8)$ & $288(47.1)$ \\
\hline \multicolumn{4}{|l|}{ Cognitive social capital } \\
\hline Emotional support & $263(89.5)$ & $226(71.3)$ & $489(80.0)$ \\
\hline Instrumental support & $203(69.1)$ & $180(56.8)$ & $383(62.7)$ \\
\hline Trust & $271(92.2)$ & $269(84.9)$ & $540(88.4)$ \\
\hline Social harmony & $286(97.3)$ & $301(95.0)$ & $587(96.1)$ \\
\hline Sense of belonging & $289(98.3)$ & $303(95.6)$ & $592(96.9)$ \\
\hline Perceived fairness & $275(93.5)$ & $301(95.0)$ & $576(94.3)$ \\
\hline \multicolumn{4}{|c|}{ Specific adverse events within the last 3 years } \\
\hline Yes & $240(81.6)$ & $248(78.2)$ & $488(79.9)$ \\
\hline Household size (Mean \pm SD) & $3.5 \pm 1.4$ & $3.5 \pm 1.4$ & $3.5 \pm 1.4$ \\
\hline \multicolumn{4}{|l|}{ Individual level } \\
\hline Number of participants & $646(42.3)$ & $882(57.7)$ & $1528(100 \%)$ \\
\hline \multicolumn{4}{|l|}{ Age } \\
\hline 17-24 years old & $80(12.4)$ & $108(12.2)$ & $188(12.3)$ \\
\hline $25-49$ years old & $251(38.8)$ & $434(49.2)$ & $685(44.8)$ \\
\hline $50+$ years old & $315(48.8)$ & $340(38.6)$ & $655(42.9)$ \\
\hline \multicolumn{4}{|l|}{ Gender } \\
\hline Male & $288(44.6)$ & $389(44.1)$ & $677(44.3)$ \\
\hline Female & $358(55.4)$ & $493(55.9)$ & $851(55.7)$ \\
\hline \multicolumn{4}{|l|}{ Education } \\
\hline Up to completed primary school & $159(24.6)$ & $464(52.6)$ & $623(40.8)$ \\
\hline Completed secondary school & $439(68.0)$ & $334(37.9)$ & $773(50.6)$ \\
\hline Any post-secondary qualification & $48(7.4)$ & $84(9.5)$ & $132(8.6)$ \\
\hline
\end{tabular}


Table 3 Univariable comparison of characteristics of people with or without a SRQ20 score $>6$

\begin{tabular}{|c|c|c|c|c|}
\hline & $\begin{array}{l}\text { People without clinically significant symptoms } \\
\text { of CMDs } \\
\mathrm{n}(\%)\end{array}$ & $\begin{array}{l}\text { People with clinically significant } \\
\text { symptoms CMDs } \\
\text { n (\%) }\end{array}$ & $\begin{array}{l}\text { Total } \\
\text { n (\%) }\end{array}$ & $P$-value \\
\hline \multicolumn{5}{|l|}{ Sex } \\
\hline Male & $588(46.1)$ & $89(35.5)$ & $\begin{array}{l}677 \\
(44.3)\end{array}$ & 0.002 \\
\hline Female & $689(53.9)$ & $162(64.5)$ & $\begin{array}{l}851 \\
(55.7)\end{array}$ & \\
\hline \multicolumn{5}{|l|}{ Age } \\
\hline 17-24 years old & $176(13.8)$ & $12(4.8)$ & $\begin{array}{l}188 \\
(12.3)\end{array}$ & $<0.001$ \\
\hline 25-49years old & $610(47.8)$ & $75(29.9)$ & $\begin{array}{l}685 \\
(44.8)\end{array}$ & \\
\hline $50+$ years old & $491(38.4)$ & $164(65.3)$ & $\begin{array}{l}655 \\
(42.9)\end{array}$ & \\
\hline \multicolumn{5}{|l|}{ Education } \\
\hline $\begin{array}{l}\text { Up to completion of primary } \\
\text { school }\end{array}$ & $502(39.3)$ & $121(48.2)$ & $\begin{array}{l}623 \\
(40.8)\end{array}$ & $<0.001$ \\
\hline $\begin{array}{l}\text { Completion of secondary or high } \\
\text { school }\end{array}$ & $648(50.7)$ & $125(49.8)$ & $\begin{array}{l}773 \\
(50.6)\end{array}$ & \\
\hline TAFE/ bachelor/postgraduate & $127(10.0)$ & $5(2.0)$ & $\begin{array}{l}132 \\
(8.6)\end{array}$ & \\
\hline
\end{tabular}

(specific collective actions, links to groups with resources, instrumental support, and social harmony) (see Table 4).

After conducting the multilevel mixed-effects logistic regression, participants who were younger than 24 years old versus $50+$ group, male and had completed tertiary education were less likely to experience clinically significant symptoms of common mental disorders. Households in the southern province, having advantaged economic status, having no member experiencing alcohol abuse, having links to groups with resources and receiving instrumental support were protected against CMDs among their family members (see Table 5).

\section{Associated factors of SMDs}

In the uncontrolled univariate analyses, at individual level, gender, age, and education were not significantly associated with symptoms of SMDs (see Table 6). Household's factors associated with any psychotic symptom were province, residence, and economic status (see Table 7).

The multilevel mixed-effects logistic regression analysis revealed that, people aged at least 50 years were more likely to report symptoms of SMDs than those in the 17-24 years old group. Households in the southern province, having mid-level or advantaged economic status and having no family violence were less likely to have family members with any psychotic symptom (see Table 8).

\section{Discussion}

To our knowledge, this is the first household survey conducted in both southern and northern provinces to estimate the burden of common and severe mental disorders among adults in Vietnam. A rigorous random selection method was used in each implementation step and there was a high recruitment fraction (95\%). The data were collected by local language speakers to maximize the likelihood that participants could comprehend the questions. The data sources were developed in Vietnam and the indicator of the primary outcome of the SRQ20 had been formally validated to establish the local cut-off scores for clinically significant symptoms with high sensitivity and specificity in the country.

In rural provinces in Vietnam, it is common for people to migrate internally to secure income-generating work. Elderly and young people are more likely to stay at home to farm while people of working age migrate to urban centres for paid employment. In order to take this into account, prevalence estimates were weighted by age group according to the national household survey conducted in the same year. No previous comparable studies in Vietnam have made this adjustment.

Nevertheless, we acknowledge some limitations in the study.

Relevant information about individuals was not ascertained directly, but was sought from household heads. This practice, while common in household surveys in LMICs introduces potential biases, which might reduce 
Table 4 Univariable comparison of characteristics of households with or without a member with SRQ20 scores $>6$

\begin{tabular}{|c|c|c|c|c|}
\hline & $\begin{array}{l}\text { Household with no members having clinically } \\
\text { significant symptoms of CMDs } \\
\text { n (\%) }\end{array}$ & $\begin{array}{l}\text { Household with members having clinically } \\
\text { significant symptoms of CMDs } \\
n(\%)\end{array}$ & $\begin{array}{l}\text { Total } \\
\text { n (\%) }\end{array}$ & $\begin{array}{l}P_{-} \\
\text {value }\end{array}$ \\
\hline \multicolumn{5}{|l|}{ Province } \\
\hline Thanh Hoa (north) & $230(45.9)$ & $64(58.2)$ & $\begin{array}{l}294 \\
(48.1)\end{array}$ & 0.02 \\
\hline Ben Tre (south) & $271(54.1)$ & $46(41.8)$ & $\begin{array}{l}317 \\
(51.9)\end{array}$ & \\
\hline \multicolumn{5}{|l|}{ Residence } \\
\hline Urban & $189(37.7)$ & $30(27.3)$ & $\begin{array}{l}219 \\
(35.8)\end{array}$ & 0.01 \\
\hline Rural & $212(62.3)$ & $80(72.7)$ & $\begin{array}{l}392 \\
(64.2)\end{array}$ & \\
\hline $\begin{array}{l}\text { Household size (Mean } \pm \\
\text { SD) }\end{array}$ & $3.5 \pm 1.4$ & $3.3 \pm 1.4$ & $\begin{array}{l}3.5 \pm \\
1.4\end{array}$ & 0.08 \\
\hline \multicolumn{5}{|l|}{ Economic status } \\
\hline Disadvantaged & $73(14.6)$ & $28(25.5)$ & $\begin{array}{l}101 \\
(16.5)\end{array}$ & 0.03 \\
\hline Mid-level & $296(59.1)$ & $59(53.6)$ & $\begin{array}{l}355 \\
(58.1)\end{array}$ & \\
\hline Advantaged & $132(26.3)$ & $23(20.9)$ & $\begin{array}{l}155 \\
(25.4)\end{array}$ & \\
\hline Alcohol abuse & $53(10.6)$ & $22(20.0)$ & $\begin{array}{l}75 \\
(12.3)\end{array}$ & 0.06 \\
\hline $\begin{array}{l}\text { Family violence (Mean } \pm \\
\text { SD) }\end{array}$ & $4.0 \pm 0.2$ & $4.0 \pm 0.2$ & $\begin{array}{l}4.0 \pm \\
0.2\end{array}$ & 0.3 \\
\hline \multicolumn{5}{|l|}{ Structural social capital } \\
\hline $\begin{array}{l}\text { Participation in } \\
\text { organizations }\end{array}$ & $185(36.9)$ & $32(29.1)$ & $\begin{array}{l}217 \\
(35.5)\end{array}$ & 0.1 \\
\hline Degree of citizenship & $351(70.1)$ & $80(72.7)$ & $\begin{array}{l}431 \\
(70.5)\end{array}$ & 0.5 \\
\hline $\begin{array}{l}\text { Specific collective } \\
\text { actions }\end{array}$ & $195(38.9)$ & $31(28.2)$ & $\begin{array}{l}226 \\
(37.0)\end{array}$ & 0.03 \\
\hline $\begin{array}{l}\text { Links to groups with } \\
\text { resources }\end{array}$ & $246(49.1)$ & $42(38.2)$ & $\begin{array}{l}288 \\
(47.1)\end{array}$ & 0.003 \\
\hline \multicolumn{5}{|l|}{ Cognitive social capital } \\
\hline Emotional support & $398(79.4)$ & $91(82.7)$ & $\begin{array}{l}489 \\
(80.0)\end{array}$ & 0.4 \\
\hline Instrumental support & $327(65.3)$ & $56(50.9)$ & $\begin{array}{l}383 \\
(62.7)\end{array}$ & 0.005 \\
\hline Trust & $446(89.0)$ & $94(85.5)$ & $\begin{array}{l}540 \\
(88.4)\end{array}$ & 0.2 \\
\hline Social harmony & $485(96.8)$ & $102(92.7)$ & $\begin{array}{l}587 \\
(96.1)\end{array}$ & 0.04 \\
\hline Sense of belonging & $485(96.8)$ & $107(97.3)$ & $\begin{array}{l}592 \\
(96.9)\end{array}$ & 0.7 \\
\hline Perceived fairness & $475(94.8)$ & $101(91.8)$ & $\begin{array}{l}576 \\
(94.3)\end{array}$ & 0.2 \\
\hline $\begin{array}{l}\text { Adverse events within } \\
\text { the last } 3 \text { years }\end{array}$ & $99(19.8)$ & $24(21.8)$ & $\begin{array}{l}123 \\
(20.1)\end{array}$ & 0.6 \\
\hline
\end{tabular}


Table 5 Adjusted odd ratios of household and individual characteristics of adults with and without SRQ20 scores> 6 in Vietnam

\begin{tabular}{|c|c|c|c|}
\hline Factors & Adjusted OR & $95 \% \mathrm{Cl}$ & $P$-value \\
\hline \multicolumn{4}{|l|}{ Age } \\
\hline \multicolumn{4}{|l|}{ 0-17-24 years old (reference group) } \\
\hline $25-49$ years old & 1.69 & $0.83-3.43$ & 0.1 \\
\hline $50+$ years old & 4.64 & $2.27-9.47$ & $<0.001$ \\
\hline \multicolumn{4}{|l|}{ Gender } \\
\hline \multicolumn{4}{|l|}{ Male (reference group) } \\
\hline Female & 1.59 & $1.14-2.21$ & 0.006 \\
\hline \multicolumn{4}{|l|}{ Education } \\
\hline \multicolumn{4}{|c|}{ TAFE/bachelor/postgraduate (reference group) } \\
\hline Completion of secondary or high school & 3.73 & $1.35-10.38$ & 0.01 \\
\hline Up to completion of primary school & 4.57 & $1.61-13.0$ & 0.004 \\
\hline \multicolumn{4}{|l|}{ Province } \\
\hline \multicolumn{4}{|c|}{ Thanh Hoa (northern Vietnam) (reference group) } \\
\hline Ben Tre (southern Vietnam) & 0.48 & $0.30-0.75$ & 0.002 \\
\hline \multicolumn{4}{|l|}{ Economic status } \\
\hline \multicolumn{4}{|l|}{ Disadvantaged (reference group) } \\
\hline Mid-level & 0.62 & $0.38-1.01$ & 0.06 \\
\hline Advantaged & 0.53 & $0.29-0.98$ & 0.04 \\
\hline \multicolumn{4}{|l|}{ Residence } \\
\hline \multicolumn{4}{|l|}{ Urban (reference group) } \\
\hline Rural & 1.02 & $0.66-1.59$ & 0.9 \\
\hline Household size & 1.01 & $0.89-1.15$ & 0.8 \\
\hline \multicolumn{4}{|l|}{ Alcohol abuse } \\
\hline \multicolumn{4}{|l|}{ No (reference group) } \\
\hline Yes & 1.80 & $1.06-3.06$ & 0.03 \\
\hline \multicolumn{4}{|l|}{ Family violence } \\
\hline \multicolumn{4}{|l|}{ No (reference group) } \\
\hline Yes & 1.99 & $0.71-5.58$ & 0.1 \\
\hline \multicolumn{4}{|l|}{ Structural social capital } \\
\hline \multicolumn{4}{|l|}{ Participation in organizations } \\
\hline \multicolumn{4}{|l|}{ Yes (reference group) } \\
\hline No & 1.08 & $0.70-1.65$ & 0.7 \\
\hline \multicolumn{4}{|l|}{ Degree of citizenship } \\
\hline \multicolumn{4}{|l|}{ Yes (reference group) } \\
\hline No & 1.02 & $0.67-1.57$ & 0.9 \\
\hline \multicolumn{4}{|l|}{ Specific collective action } \\
\hline \multicolumn{4}{|l|}{ Yes (reference group) } \\
\hline No & 0.77 & $0.50-1.19$ & 0.2 \\
\hline \multicolumn{4}{|l|}{ Links to groups with resources } \\
\hline \multicolumn{4}{|l|}{ Yes (reference group) } \\
\hline No & 1.83 & $1.16-2.88$ & 0.009 \\
\hline Cognitive social capital & & & \\
\hline Emotional support & & & \\
\hline Yes (reference group) & & & \\
\hline
\end{tabular}


Table 5 Adjusted odd ratios of household and individual characteristics of adults with and without SRQ20 scores $>6$ in Vietnam (Continued)

\begin{tabular}{|c|c|c|c|}
\hline Factors & Adjusted OR & $95 \% \mathrm{Cl}$ & $P$-value \\
\hline No & 1.45 & $0.85-2.49$ & 0.1 \\
\hline \multicolumn{4}{|c|}{ Instrumental support } \\
\hline \multicolumn{4}{|c|}{ Yes (reference group) } \\
\hline No & 1.56 & $1.04-2.34$ & 0.03 \\
\hline \multicolumn{4}{|c|}{ Trust of community } \\
\hline \multicolumn{4}{|c|}{ Yes (reference group) } \\
\hline No & 1.23 & $0.65-2.33$ & 0.5 \\
\hline \multicolumn{4}{|c|}{ Social harmony } \\
\hline \multicolumn{4}{|c|}{ Yes (reference group) } \\
\hline No & 1.75 & $0.62-4.90$ & 0.2 \\
\hline \multicolumn{4}{|c|}{ Sense of belonging } \\
\hline \multicolumn{4}{|c|}{ Yes (reference group) } \\
\hline No & 1.01 & $0.32-3.22$ & 0.9 \\
\hline \multicolumn{4}{|c|}{ Perceived fairness } \\
\hline \multicolumn{4}{|c|}{ Yes (reference group) } \\
\hline No & 1.88 & $0.91-3.85$ & 0.08 \\
\hline \multicolumn{4}{|c|}{ Adverse life events in the last 3 years } \\
\hline \multicolumn{4}{|c|}{ No (reference group) } \\
\hline Yes & 1.00 & $0.64-1.58$ & 0.9 \\
\hline
\end{tabular}

precision of prevalence estimates and accuracy of associations with risk and protective factors. There is a likely gender bias in that most household heads are men and might have limited understanding or appreciation of the experiences of women. Additionally, household heads may have been unlikely to disclose their own perpetration of family violence or alcohol abuse. These risks are therefore most likely to be underestimated.
Alcohol abuse was not fully investigated. It was addressed by asking one question to the household heads to ascertain whether any family member was misusing alcohol. The definition of alcohol abuse was likely to have varied among household heads and was not defined clearly by the research team [15].

Finally, SRQ is a psychometric tool which was used to identify probable cases of clinically significant symptoms

Table 6 Univariable comparison of characteristics of people with or without any psychotic symptoms

\begin{tabular}{|c|c|c|c|c|}
\hline & $\begin{array}{l}\text { People without any psychotic symptoms } \\
\mathrm{n}(\%)\end{array}$ & $\begin{array}{l}\text { People with any psychotic symptoms } \\
\mathrm{n}(\%)\end{array}$ & $\begin{array}{l}\text { Total } \\
\text { n (\%) }\end{array}$ & $P$-value \\
\hline \multicolumn{5}{|l|}{ Gender } \\
\hline Male & $628(45.0)$ & $49(37.1)$ & $677(44.3)$ & \multirow[t]{2}{*}{0.08} \\
\hline Female & $768(55.0)$ & $83(62.9)$ & $851(55.7)$ & \\
\hline \multicolumn{5}{|l|}{ Age } \\
\hline 17-24 years old & $178(12.8)$ & $10(7.6)$ & $188(12.3)$ & \multirow[t]{3}{*}{0.08} \\
\hline 25-49years old & $630(45.1)$ & $55(41.7)$ & $685(44.8)$ & \\
\hline $50+$ years old & $588(42.1)$ & $67(50.8)$ & $655(42.9)$ & \\
\hline \multicolumn{5}{|l|}{ Education } \\
\hline Up to completion of primary school & $576(41.3)$ & 47 (35.6) & $623(40.8)$ & \multirow[t]{3}{*}{0.4} \\
\hline Completion of secondary or high school & $701(50.2)$ & $72(54.6)$ & $773(50.6)$ & \\
\hline TAFE/ bachelor/postgraduate & $119(8.5)$ & $13(9.8)$ & $132(8.6)$ & \\
\hline
\end{tabular}


Table 7 Univariable comparison of characteristics of households with or without a member with at least one psychotic symptom

\begin{tabular}{|c|c|c|c|c|}
\hline & $\begin{array}{l}\text { Household with no members having any } \\
\text { symptom of SMDs } \\
\text { n (\%) }\end{array}$ & $\begin{array}{l}\text { Household with members having any } \\
\text { symptom of SMDs } \\
n(\%)\end{array}$ & $\begin{array}{l}\text { Total } \\
\text { n (\%) }\end{array}$ & $P$-value \\
\hline \multicolumn{5}{|l|}{ Province } \\
\hline Thanh Hoa (north) & $260(46.9)$ & $34(60.7)$ & $\begin{array}{l}294 \\
(48.1)\end{array}$ & 0.04 \\
\hline Ben Tre (south) & $295(53.1)$ & $22(39.3)$ & $\begin{array}{l}317 \\
(51.9)\end{array}$ & \\
\hline \multicolumn{5}{|l|}{ Residence } \\
\hline Urban & $207(37.3)$ & $12(21.4)$ & $\begin{array}{l}219 \\
(35.8)\end{array}$ & 0.01 \\
\hline Rural & $348(62.7)$ & $44(78.6)$ & $\begin{array}{l}392 \\
(64.2)\end{array}$ & \\
\hline Household size (Mean \pm SD) & $3.5 \pm 1.4$ & $3.3 \pm 1.4$ & $\begin{array}{l}3.5 \pm \\
1.4\end{array}$ & 0.08 \\
\hline \multicolumn{5}{|l|}{ Economic status } \\
\hline Disadvantaged & $83(14.9)$ & $18(32.1)$ & $\begin{array}{l}101 \\
(16.5)\end{array}$ & 0.002 \\
\hline Mid-level & $325(58.6)$ & $30(53.6)$ & $\begin{array}{l}355 \\
(58.1)\end{array}$ & \\
\hline Advantaged & $147(26.5)$ & $8(14.3)$ & $\begin{array}{l}155 \\
(25.4)\end{array}$ & \\
\hline Alcohol abuse & $71(12.8)$ & $4(7.1)$ & $\begin{array}{l}75 \\
(12.3)\end{array}$ & 0.2 \\
\hline Family violence (Mean \pm SD) & $4.0 \pm 0.2$ & $4.1 \pm 0.04$ & $\begin{array}{l}4.0 \pm \\
0.2\end{array}$ & 0.1 \\
\hline \multicolumn{5}{|l|}{ Structural social capital } \\
\hline $\begin{array}{l}\text { Participation in } \\
\text { organizations }\end{array}$ & $200(36.0)$ & $17(30.4)$ & $\begin{array}{l}217 \\
(35.5)\end{array}$ & 0.3 \\
\hline Degree of citizenship & $393(70.8)$ & $38(67.9)$ & $\begin{array}{l}431 \\
(70.5)\end{array}$ & 0.5 \\
\hline Specific collective action & $204(36.8)$ & $22(39.3)$ & $\begin{array}{l}226 \\
(37.0)\end{array}$ & 0.7 \\
\hline $\begin{array}{l}\text { Links to groups with } \\
\text { resources }\end{array}$ & $267(48.1)$ & $21(37.5)$ & $\begin{array}{l}288 \\
(47.1)\end{array}$ & 0.1 \\
\hline \multicolumn{5}{|l|}{ Cognitive social capital } \\
\hline Emotional support & $442(79.6)$ & $47(83.9)$ & $\begin{array}{l}489 \\
(80.0)\end{array}$ & 0.4 \\
\hline Instrumental support & $354(63.8)$ & $29(51.8)$ & $\begin{array}{l}383 \\
(62.7)\end{array}$ & 0.07 \\
\hline Trust & $489(88.1)$ & $51(91.1)$ & $\begin{array}{l}540 \\
(88.4)\end{array}$ & 0.5 \\
\hline Social harmony & $533(96.0)$ & $54(96.4)$ & $\begin{array}{l}587 \\
(96.1)\end{array}$ & 0.8 \\
\hline Sense of belonging & $538(96.9)$ & $54(96.4)$ & $\begin{array}{l}592 \\
(96.9)\end{array}$ & 0.8 \\
\hline Perceived fairness & $522(94.1)$ & $54(96.4)$ & $\begin{array}{l}576 \\
(94.3)\end{array}$ & 0.4 \\
\hline $\begin{array}{l}\text { Adverse events within the last } \\
3 \text { years }\end{array}$ & $113(20.4)$ & $10(17.9)$ & $\begin{array}{l}123 \\
(20.1)\end{array}$ & 0.6 \\
\hline
\end{tabular}


Table 8 Adjusted odd ratios of household and individual characteristics of adults with and without any psychotic symptom 6 in Vietnam

\begin{tabular}{|c|c|c|c|}
\hline Factors & Adjusted OR & $95 \% \mathrm{Cl}$ & $P$-value \\
\hline \multicolumn{4}{|l|}{ Age } \\
\hline \multicolumn{4}{|l|}{ 17-24 years old (reference group) } \\
\hline 25-49years old & 2.15 & $0.98-4.71$ & 0.06 \\
\hline $50+$ years old & 2.83 & $1.26-6.38$ & 0.01 \\
\hline \multicolumn{4}{|l|}{ Gender } \\
\hline \multicolumn{4}{|l|}{ Male (reference group) } \\
\hline Female & 1.42 & $0.94-2.14$ & 0.09 \\
\hline \multicolumn{4}{|l|}{ Education } \\
\hline \multicolumn{4}{|c|}{ TAFE/bachelor/postgraduate (reference group) } \\
\hline Completion of secondary or high school & 0.69 & $0.32-1.49$ & 0.3 \\
\hline Up to completion of primary school & 0.47 & $0.20-1.09$ & 0.07 \\
\hline \multicolumn{4}{|l|}{ Province } \\
\hline \multicolumn{4}{|c|}{ Thanh Hoa (northern Vietnam) (reference group) } \\
\hline Ben Tre (southern Vietnam) & 0.54 & $0.31-0.95$ & 0.03 \\
\hline \multicolumn{4}{|l|}{ Economic status } \\
\hline \multicolumn{4}{|l|}{ Disadvantaged (reference group) } \\
\hline Mid-level & 0.50 & $0.27-0.91$ & 0.02 \\
\hline Advantaged & 0.35 & $0.16-0.75$ & 0.007 \\
\hline \multicolumn{4}{|l|}{ Residence } \\
\hline \multicolumn{4}{|l|}{ Urban (reference group) } \\
\hline Rural & 1.25 & $0.72-2.16$ & 0.4 \\
\hline Household size & 1.00 & $0.85-1.18$ & 0.9 \\
\hline \multicolumn{4}{|l|}{ Alcohol abuse } \\
\hline \multicolumn{4}{|l|}{ No (reference group) } \\
\hline Yes & 0.58 & $0.26-1.30$ & 0.1 \\
\hline \multicolumn{4}{|l|}{ Family violence } \\
\hline \multicolumn{4}{|l|}{ No (reference group) } \\
\hline Yes & 3.50 & $1.08-11.31$ & 0.03 \\
\hline \multicolumn{4}{|l|}{ Structural social capital } \\
\hline \multicolumn{4}{|l|}{ Participation in organizations } \\
\hline \multicolumn{4}{|l|}{ Yes (reference group) } \\
\hline No & 1.02 & $0.60-1.72$ & 0.9 \\
\hline \multicolumn{4}{|l|}{ Degree of citizenship } \\
\hline \multicolumn{4}{|l|}{ Yes (reference group) } \\
\hline No & 1.00 & $0.57-1.71$ & 0.9 \\
\hline \multicolumn{4}{|l|}{ Specific collective action } \\
\hline \multicolumn{4}{|l|}{ Yes (reference group) } \\
\hline No & 1.12 & $0.65-1.92$ & 0.6 \\
\hline \multicolumn{4}{|l|}{ Links to groups with resources } \\
\hline \multicolumn{4}{|l|}{ Yes (reference group) } \\
\hline No & 1.01 & $0.58-1.75$ & 0.9 \\
\hline Cognitive social capital & & & \\
\hline Emotional support & & & \\
\hline
\end{tabular}


Table 8 Adjusted odd ratios of household and individual characteristics of adults with and without any psychotic symptom 6 in Vietnam (Continued)

\begin{tabular}{|c|c|c|c|}
\hline Factors & Adjusted OR & $95 \% \mathrm{Cl}$ & $P$-value \\
\hline \multicolumn{4}{|c|}{ Yes (reference group) } \\
\hline No & 1.27 & $0.65-2.49$ & 0.4 \\
\hline \multicolumn{4}{|c|}{ Instrumental support } \\
\hline \multicolumn{4}{|c|}{ Yes (reference group) } \\
\hline No & 1.54 & $0.93-2.56$ & 0.09 \\
\hline \multicolumn{4}{|c|}{ Trust of community } \\
\hline \multicolumn{4}{|c|}{ Yes (reference group) } \\
\hline No & 1.37 & $0.63-2.98$ & 0.4 \\
\hline \multicolumn{4}{|c|}{ Social harmony } \\
\hline \multicolumn{4}{|c|}{ Yes (reference group) } \\
\hline No & 1.10 & $0.28-4.35$ & 0.8 \\
\hline \multicolumn{4}{|c|}{ Sense of belonging } \\
\hline \multicolumn{4}{|c|}{ Yes (reference group) } \\
\hline No & 0.87 & $0.18-4.24$ & 0.8 \\
\hline \multicolumn{4}{|c|}{ Perceived fairness } \\
\hline \multicolumn{4}{|c|}{ Yes (reference group) } \\
\hline No & 0.55 & $0.18-1.65$ & 0.2 \\
\hline \multicolumn{4}{|c|}{ Adverse life events in the last 3 years } \\
\hline \multicolumn{4}{|c|}{ No (reference group) } \\
\hline Yes & 1.06 & $0.60-1.87$ & 0.8 \\
\hline
\end{tabular}

of CMDs and SMDs in community [12]. In other words, this tool indicates that it cannot provide a diagnosis as a diagnostic instrument. Therefore, SRQ results can only suggest potential burden of mental disorders in a population.

Despite these limitations which we believe are more likely to have led to under rather than overestimates of prevalence, we believe the data provide a generalizable indication of the burden and potentially modifiable risks for mental disorders in Vietnam.

\section{Prevalence of clinically significant symptoms of CMDs and SMDs in Vietnam and other countries}

Overall, the prevalence of clinically significant symptoms of CMDs and SMDs among people who are aged at least 16 years old in this study was more than $22 \%$ after age standardization. The raw prevalence of clinically significant symptoms of CMDs was around 20\%, which is similar to other studies using SRQ20 [16, 17]. However, there were people who had both clinically significant symptoms of CMDS and SMDs which was included in the group of having CMDs. The DSM-5 reported that people with psychotic disorders may sometimes experience several depressive and anxiety periods during their lifetime [29]. Therefore, after excluding those people in the CMDs' group, the prevalence reduced from around $20 \%$ to just over $14 \%$.

The rate of clinically significant symptoms of CMDs is lower than other studies using SRQ20 among adults in southern provinces $[16,17]$. There are several factors contributing to the difference. First, it is due to the deduction of people having both CMDs and SMDs symptoms. Second, the difference may be due to the different cut-off point $(7 / 8)$ and lack of age standardization. However, the result of this study is higher compared to other three studies $[14,15,32]$. The study conducted by Kim Bao Giang et al. reported a low prevalence (5.4\%) using the same screening tool (SRQ20). Differences in age distribution and geographical area may be the possible explanations. Giang et al's study was implemented among adults from 18 to 60 years old and was not weighted with the standard age distribution of Vietnam. In addition, $\mathrm{Ba} \mathrm{Vi}$ is a northern district of Hanoi city, which is around $60 \mathrm{~km}$ from the centre of Hanoi. Therefore, the socio-economic status may be more advantaged compared to our study population which may lead to the lower rate of CMDs than our study [32]. Different psychometric instruments used across studies for identifying the burden of mental health problems are also considered as a reason of the difference. The study conducted by Steel et al. in a southern province use CIDI - a diagnostic tool with cultural adaptation [15]. 
The rate of depression and anxiety reported in the Vuong et al. paper did not provide sufficient details for discussion of the difference [14].

Our finding of $8.6 \%$ of SMDs was higher than the result in Vietnam (0.66\%), but lower than the prevalence of low and middle income countries (12.9\%) which were reported by a WHO multi-country study using CIDI [13]. The rate of respondents having one or more psychotic symptoms in this survey is higher than the prevalence of schizophrenia published by the Ministry of Health (0.5\%) [14]. The World Health Survey used CIDI - a diagnostic tool and the Vietnam government's prevalence is believed to employ diagnostic instruments because it was estimated by the public mental health hospitals which may explain the different findings. However, due to the limitation to access to full report of the Ministry of Health's report, therefore, it is hard to provide further evidence for the difference.

\section{Determinants of CMDs among different demographic groups}

Regarding individual factors, there was a larger proportion of people with CMDs among women than man which was consistent with other studies [32, 33]. It may due to gender inequity which creates a significant burden on women in Vietnam. In this study, people who are older than 50 years old faced a significant higher risk of both CMDs and SMDs compared to the 15-24 years old while others presented that CMDs were even less than in elderly or no association [6, 32, 34, 35]. It can be explained that, in rural Vietnam, most study participants were farmers, therefore the older they were, the less probability to have a secure income from their farming. As a result, they were more likely to experience financial difficulties compared to younger participants. Illiteracy was found to be a risk factor for CMDs $[32,36]$. The reason may be that there is a strong link between education level and employment status. People with low literacy are less likely to get a job, they may have lower income. Therefore, less educated people had higher risk of experience CMDs.

In terms of determinants at the family level, living in Ben Tre (the southern province), and in a more economically advantaged household were found to independently protect adults from SMDs and CMDs. It can be seen that Ben Tre province is wealthier and has more natural resources compared to Thanh Hoa - a poor province in the north of Vietnam. Therefore, the hard-living condition in the north province contributed to the higher prevalence of both SMDs and CMDs. Similarly, households having more advantaged economic status compared to the disadvantaged group were less likely to have family members experience CMDs and SMDs. This result was confirmed by other studies in LMICs [32, 37, 38]. It is also well known that there was a strong link between poverty and CMDs in LMICs by Lund and et al. [36]. Another household factor found to be associated with CMDs was there being at least one member experiencing alcohol abuse in the family. It may be that having at least one family member misusing alcohol increases the risk of both physical and emotional violence, and poverty. These risks, in turns, affect to the mental health of family members negatively [16, 39-42]. However, due to the acknowledged limitation in examining the family violence in this study, hence, there was no association between CMDs and this factor.

It is believed that emotional support tends to be the most effective method when someone is experiencing depressive or anxiety symptoms [43]. However, this analysis did not find this association. The data showed that having no instrumental support or no link to groups with resources was associated with CMDs. In this study, households having disadvantaged economic status were more likely to have family members experiencing CMDs. This may suggest that material support (for example: money, food) meets the basic needs of these households and alleviates their stress. In return, it may improve their mental health.

\section{Determinants SMDs among different demographic groups}

At individual level, we can only speculate on the reason for their being a higher prevalence of SMD symptoms among older than younger people. It may due to the three underlying reasons. First, it was reported in a recent population-based survey that among current drinkers, those aged around 50+ years old consumed the most alcohol [44]. Alcohol abuse is believed to be associated with psychosis [29]. Second, there are no community-based mental health services to provide assessment, diagnosis or treatment for people with psychotic symptoms in rural Vietnam. This service is only provided in custodial psychiatric hospitals. These are stigmatised institutions, about which people generally feel cautious. In addition, many people in rural areas have disadvantaged economic circumstances and cannot afford the travel costs to go to psychiatric hospitals [45]. These might lead to prolonged delays to diagnosis and treatment among people in the $50+$ age group. Third, another reason may be the late onset psychosis. A recent study showed that there is not a small number of cases having psychotic symptoms in the late life [46]. In addition, there was a strong link between people who were up to completion of primary school and psychotic symptoms. Substantial evidence of the association between school performance and psychotic disorders was established $[47,48]$. Early cognitive alteration was believed to hinder the education achievement.

At household level, similar to the associating factors of CMDs, residence and economic status had significant link to SMDs. At the time that the survey was conducted, the average income per capital per month in the Southern province was higher than that in the Northern 
province. In addition, the relationship between economic disadvantage and psychotic symptoms was well established in previous research studies [49, 50]. People having psychotic symptoms are less likely to have stable incomes and more likely to live in poverty due to their low productivity [51], limited educational level [52]. Family violence was found as a risk factor of having psychotic symptoms in this study. On the basis of this data, it is not possible to identify who is the perpetrator of the family violence. People with SMDs might be the victim, or the perpetrator, or the witness of the family violence. A systematic review of 41 studies conducted by Trevillion et al. in 2012 found that people with SMDs were at risk of experiencing domestic violence [53]. However, included studies were reported to have limited quality in terms of selection bias, sample representativeness, and impact of non-participation. In addition, domestic violence was measured using various methods such as different time periods, types of violence, and instruments. On the other hand, a study mentioned the burden of violent behaviour among caregivers of people with schizophrenia and bipolar disorders. With the sample of 243 schizophrenic patients and 200 bipolar patients recruited within 1 week of patient's admission to the mental health hospital, Zhou et al. found that caregivers of people with bipolar disorders experienced more violent burden than those of schizophrenic people [54]. The findings were reported among recent admission patients, hence, the caregivers may experience significant burden than the people with SMI in the community due to the patients' acute symptoms. In addition, due to the domestic violence, people were more likely to admit the question of "somebody has been trying to harm you in some way".

\section{Conclusions}

The study found that among people who are older than 16 years old, around $14 \%$ of them experienced CMDs and approximately $8 \%$ had symptoms of SMDs. This burden indicates the need for early detection at primary health care. In addition, except for gender and age, most common influencing factors related to family level. The result suggests that instead of focusing on the individual level, the community-based mental health model in Decision 1215 should focus on reducing family hazards such as family violence and providing instrumental support and access to resource groups to those in need.

\footnotetext{
Abbreviations

CIDI: Composite International Diagnostic Interview; CMD: Common mental disorders; HICs: High income countries; HITS: Hurts, Insults, Threatens and Screams; LMICs: Low and middle-income countries; RTCCD: Research and Training Centre for Community Development; SASCAT: Short version of the modified Adapted Social Capital Assessment Tool; SMD: Severe mental disorders; SRQ: Self-reporting Questionnaire; WHO: World Health Organization; YLD: Years lived with disability
}

\section{Acknowledgments}

Trang Nguyen is supported by Monash International Postgraduate Research Scholarship. Jane Fisher is supported by the Finkel Professorial Fellowship, which is funded by Finkel Foundation. Thach Tran is supported by a National Health and Medical Research Council Early Career Fellowship.

\section{Authors' contributions \\ TUT and HT designed the study and coordinated the data collection. TN analysed the data and drafted the manuscript. ThT provided statistical support. JF provided detailed input to the reporting and interpretation of the data and revisions of the manuscript. All authors read and approved the final manuscript.}

\section{Funding}

Not applicable.

\section{Availability of data and materials}

The datasets used and/or analysed during the current study are available from the corresponding author upon reasonable request.

\section{Ethics approval and consent to participate}

This survey was approved by the Human Research Ethics Committee of Vietnam Union of Science and Technology Associations (Decision No.25/12/ QD-RTCCD) and the Monash University Human Research Ethics Committee (certificate number: 9515).

The study participants were given an oral or written plain language description of the study and were asked to sign a consent form. Those who could not write provided a thumbprint or verbal consent witnessed by an independent observer. Both Human Research Ethics Committees approved all consent procedures used.

\section{Consent for publication}

Not applicable.

\section{Competing interests}

$\mathrm{JF}$ is mental health section editor of BMC Women's Health.

Received: 29 August 2018 Accepted: 19 August 2019

Published online: 27 August 2019

\section{References}

1. Patel V. Mental health in low- and middle- income countries. Br Med Bull. 2007;81 and 82:81-96.

2. GBD 2017 Disease and Injury Incidence and Prevalence Collaborators. Global, regional, and national incidence, prevalence, and years lived with disability for 354 diseases and injuries for 195 countries and territories, 1990-2017: a systematic analysis for the Global Burden of Disease Study 2017. Lancet. 2018:392:1789-858.

3. Institute for Health Metrics and Evaluation (IHME). Findings from the global burden of disease study 2017. Seattle: IHME; 2018.

4. Vigo D, Thornicroft G, Atun R. Estimating the true global burden of mental illness. Lancet Psychiatry. 2016;3:171-8.

5. Goldberg D, Huxley P. Common mental disorders: a biosocial model. England: Tavistock/Routledge; 1992.

6. Jenkins R, Mbatia J, Singleton N, White B. Prevalence of psychotic symptoms and their risk factors in urban Tanzania. Int J Environ Res Public Health. 2010;7:2514-25.

7. World Health Organization Press. mhGAP intervention guide for mental, neurological and substance use disorders in non-specialized health settings. Geneva: World Health Organization Press; 2011.

8. World Health Organization. Depression and other common mental disorders: Global Health estimates. Geneva: World Health Organization; 2017.

9. Steel Z, Marnane C, Iranpour C, Chey T, Jackson J, Patel V, et al. The global prevalence of common mental disorders: a systematic review and metaanalysis 1980-2013. Int J Epidemiol. 2014;43(2):476-93.

10. Shrestha SD, Pradhan R, Tran TD, Gualano RC, Fisher JRW. Reliability and validity of the Edinburgh postnatal depression scale (EPDS) for detecting perinatal common mental disorders (PCMDs) among women in low-and lower-middle-income countries: a systematic review. BMC Pregnancy Childbirth. 2016;16:72.

11. van Os J, Linscott RJ, Myin-Germeys I, Delespaul P, Krabbendam L. A systematic review and meta-analysis of the psychosis continuum: evidence 
for a psychosis proneness-persistence-impairment model of psychotic disorder. Psychol Med. 2009;39:179-95.

12. World Health Organization. A user's guide to the self reporting questionnaire (SRQ). 1994.

13. Nuevo R, Chatterji S, Verdes E, Naidoo N, Arango C, Ayuso-Mateos JL. The continuum of pyschotic symptoms in the general poppulation: a crossnational study. Schizophr Bull. 2012;38(3):475-85.

14. Vuong DA, Ginneken EV, Morris J, Ha ST, Busse R. Mental health in Vietnam: burden of disease and availability of services. Asian J Psychiatr. 2011;4(1):65-70

15. Steel Z, Silove D, Giao NM, Phan TTB, Chey T, Whelan A, et al. International and indigenous diagnoses of mental disorder among Vietnamese living in Vietnam and Australia. Br J Psychiatry. 2009;194:326-33.

16. Richardson LK, Amstadter AB, Kilpatrick DG, Gaboury MT, Tran TL, Trung LT, et al. Estimating mental distress in Vietnam: the use of the SRQ-20. Int I Soc Psychiatry. 2010;56(2):133-42.

17. Amstadter AB, Acierno R, Richardson L, Kilpatrick DG, Gros DF, Gaboury MT, et al. Post-typhoon prevalence of post-traumatic stress disorder, major depressive disorder, panic disorder and generalized anxiety disorder in a Vietnamese sample. J Trauma Stress. 2009;22(3):180-8.

18. General Statistics Office. The 1/4/2014 Vietnam intercensal population and housing survey: major findings. Hanoi: General Statistics Offfice of Vietnam; 2015.

19. Thanh Hoa Portal. Vietnam Thanh Hoa Provincial People's Committe 2017. Available from: http://en-us.thanhhoa.gov.vn/portal/Pages/default.aspx. Accessed 9 Mar 2017.

20. Ben Tre Portal. Ben Tre: Ben Tre Provincial People's Comittee 2017. Available from: http://www.bentre.gov.vn/Pages/Homepage.aspx. Accessed 9 Mar 2017.

21. Tuan $T$, Harpham $T$, Nguyen $H$. Validity and reliability of the self-reporting questionnaire 20 items (SRQ20) in Vietnam. Hong Kong J Psychiatry. 2004; 14:15-8.

22. Giang KB, Allebeck $P$, Kullgren $G$, Tuan NV. The Vietnamese version of the self reporting questionnaire 20 (SRQ20) in detecting mental disorders in rural Vietnam: a validation study. Int J Soc Psychiatry. 2006;52(2):175-84

23. Vietnam General Statistics Office. Result of the Vietnma household living standards survey 2014. Hanoi: Vietnam Statistical Publishing House; 2016.

24. Sherin KM, Sinacore JM, Li X-Q, Zitter RE, Shakil A. HITS: a short domestic violence screening tool for use in a family practice setting. Fam Med. 1998; 30(7):508-12.

25. Silva M, Harpham T, Tuan T, Bartolini R, Penny ME, Huttly SR. Psychometric and cognitive validation of a social capital measurement tool in Peru and Vietnam. Soc Sci Med. 2006;62:941-53.

26. Harpham T, Grant E, Thomas E. Measuring social capital within health surveys: key issues. Health Policy Plan. 2002;17(1):106-11.

27. Silva M, Huttly SR, Harpham T, Kenward MG. Social capital and mental health: a comparative analysis of four low income countries. Soc Sci Med. 2007;64(1):5-20

28. Tuan T, Harpham T, Huong NT. Measuring social capital and mental health in Vietnam: a validity study. England: Young Lives; 2003.

29. American Psychiatric Association. Diagnostic and statistical manual of mental disorders - fifth edition - DSM-5. United States: American Psychiatric Publishing; 2013.

30. General Statistics Office of Vietnam. Vietnam population change and family planning survey in 2013. Major findings. Hanoi: General Statistics Offfice of Vietnam; 2013.

31. Austin PC, Merlo J. Intermediate and advanced topics in multilevel logistic regression analysis. Stat Med. 2017;36:3257-77.

32. Giang KB, Dzung TV, Kullgren G, Allebeck P. Prevalence of mental distress and use of health services in a rural district in Vietnam. Glob Health Action. 2010;3(1):2025.

33. World Health Organization. Gender disparities in mental health. Geneva: World Health Organization; 2001.

34. Araya R, Rojas G, Fritsch R, Acuña J, Lewis G. Common mental disorders in Santiago, Chile: prevalence and socio-demographic correlates. $\mathrm{Br}$ Psychiatry. 2001;178:228-33.

35. Strine TW, Balluz L, Chapman DP, Moriarty DG, Owens M, Mokdad AH. Risk behaviors and healthcare coverage among adults by frequent mental distress status. Am J Prev Med. 2001;26:213-6.

36. Lund C, Breen A, Flisher AJ, Kakuma R, Corrigall J, Joska JA, et al. Poverty and common mental disorders in low and middle income countries: a systematic review. Soc Sci Med. 2010;71(3):517-28.
37. Islam M, Ali M, Ferroni P, Underwood P, Alam F. Prevalence of psychiatric disorders in an urban community in Bangladesh. Gen Hosp Psychiatry. 2003; 25:353-7.

38. Patel V, Kleinman A. Poverty and common mental disorders in developing countries. Bull World Health Organ. 2003;81(8):609-15.

39. Fisher J, Tran T, La B, Kriitmaa K, Rosenthal D, Tran T. Common perinatal mental disorders in northern Viet Nam: community prevalence and health care use. Bull World Health Organ. 2010;88:737-45.

40. Fisher J, Tran T, Tran T, Dwyer T, Nguyen T, Casey GJ, et al. Prevalence and risk factors for symptoms of common mental disorders in early and late pregnancy in Vietnamese women: a prospective population-based study. J Affect Disord. 2013;146(2):213-9.

41. Angelucci M. Love on the rocks: domestic violence and alcohol abuse in rural Mexico. BE J Econ Anal Policy. 2008;8(1):1935-682.

42. Golding JM. Intimate partner violence as a risk factor for mental disorders: a meta-analysis. J Fam Violence. 1999;14(2):99-132.

43. Liabsuetrakul T, Vittayanont A, Pitanupong J. Clinical applications of anxiety, social support, stressors, and self-esteem measured during pregnancy and postpartum for screening postpartum depression in Thai women. J Obstet Gynaecol Res. 2007;33(3):333-40.

44. International Alliance for Responsible Drinking. Unrecorded alcohol in Vietnam - Results of a population survey. Vietnam: International Alliance for Responsible Drinking; 2018.

45. Research and Training Center for Community Development. Assessment of the mental health care models operated by non-governmental organizations in Vietnam. Vietnam: Research and Training Center for Community Development; 2011.

46. Nebhinani N, Pareek V, Grover S. Late-life psychosis: an overview. J Geriatr Mental Health. 2014;1 (2):60-70.

47. Frissen A, Lieverse R, Marcelis M, Drukker M. Psychotic disorder and educational achievement: a family-based analysis. Soc Psychiatry Psychiatr Epidemiol. 2015;50:1511-8.

48. MacCabe JH, Lambe MP, Cnattingius S, Torrång A, Björk C, Sham PC, et al. Scholastic achievement at age 16 and risk of schizophrenia and other psychoses: a national cohort study. Psychol Med. 2008;38(8):1133-40.

49. Sweeney S, Air T, Zannettino L, Galletly C. Psychosis, socioeconomic disadvantage, and health service use in South Australia: findings from the second Australian national survey of psychosis. Front Public Health. 2015;3:259.

50. Kirkbride JB, Barker D, Cowden F, Stamps R, Yang M, Jones PB, et al. Psychoses, ethnicity and socio-economic status. Br J Psychiatry. 2008;193(1):18-24.

51. Fox JW. Social class, mental illness, and social mobility: the social selection-drift hypothesis for serious mental illness. J Health Soc Behav. 1991;31(4):344-53.

52. McDaid D, Jenkins R, Baingana F, Ahmad R, Atun RA. Social, economic, human rights and political challenges to global mental health. Ment Health Fam Med. 2011;8(2):87-96.

53. Trevillion K, Oram S, Feder G, Howard LM. Experiences of domestic violence and mental disorders: a systematic review and meta-analysis. PLoS One. 2012;7(12):e51740.

54. Zhou Y, Rosenheck R, Mohamed S, Ou Y, Ning Y, He H. Comparison of burden among family members of patients diagnosed with schizophrenia and bipolar disorder in a large acute psychiatric hospital in China. BMC Psychiatry. 2016;16:283.

\section{Publisher's Note}

Springer Nature remains neutral with regard to jurisdictional claims in published maps and institutional affiliations.

Ready to submit your research? Choose BMC and benefit from:

- fast, convenient online submission

- thorough peer review by experienced researchers in your field

- rapid publication on acceptance

- support for research data, including large and complex data types

- gold Open Access which fosters wider collaboration and increased citations

- maximum visibility for your research: over $100 \mathrm{M}$ website views per year

At BMC, research is always in progress.

Learn more biomedcentral.com/submission 